\title{
Development Problems of Commercial Bank’s Management Pattern in Nowadays and Countermeasures Analysis
}

\author{
Xue Feng \&Qian Liu \\ The Financial Key Laboratory of Hebei Province Science and Technology, Hebei Finance University, Baoding, 071051, \\ China
}

\begin{abstract}
Since the 18th CPC National Congress, financial reform of our country has entered the fast lane, the competition of commercial banks transit from blue sea to red sea, especially the emergence of the Internet finance, causes huge competitive pressure on the current commercial banks. Only if commercial banks innovate on business model can they cope with today's competitive market environment. This paper mainly focus on the current status quo and problems of commercial banks' business model, and analyzes the operation mode that commercial banks can choose, and then proposes improved countermeasures to perfect the commercial bank management pattern in the new period.
\end{abstract}

Keywords- business model; commercial banks; in the new period.

\section{THE BUSINESS MODEL OF COMMERCIAL BANKS IN THE NEW PERIOD}

Compared with commercial banks in Europe and the United States and other developed countries, China's banking market concentration is relatively high, and the development of different commercial banks is obvious uneven. Many commercial banks' ability to use integrated operation mode exist obvious difference, so they should select mode based on the real level, thus to improve the comprehensive competitiveness of commercial banks.

\section{A. Financial holding of commercial banks operation model}

Most of China's commercial banks listed on the a-share, become career financial holding banks, so financial holding comprehensive business model became the first selection of many commercial banks. Commercial banks as the parent company, it's not only focus on main business ontology, but also work on other financial business or business activities, such as conduct securities business and insurance and fund business, etc., thus forming the mode that takes banking business as the main body in financial industry, and actively involves in other service mode. At present our country's commercial bank's shareholding system reform is merely to finish at the beginning of this century, because the development started relatively late. And long-term decentralized management thought has also blocked the development of the integrated operation mode of commercial banks, and the career holding bank belongs to shallow integrated business management pattern, to realize the comprehensive business model, it is a transition phase, the risk can't be ignored. And the financial risk will continue fermentation as the transition from the career holding pattern to the pure financial holding comprehensive management pattern, and the ability to cope with the financial risks of commercial banks in China is relatively low, so to speed up the reform, it is very important to reduce the speed into the pure financial holding company model.

\section{B. Comprehensive management pattern based on business cooperation}

Relative to the traditional four big commercial banks in our country, many regional commercial banks in our country involved relatively small in the business of stock due to smaller scale funding, it's particularly difficult to satisfy this condition if regional commercial banks enter into pure financial holding comprehensive management pattern as large commercial banks do, but regional commercial banks have their own advantage due to small volume, so they have strong innovating ability. For example, if regional commercial banks can have deeper knowledge of the local financier's demand, then they can develop some corresponding commodity in view of the financial needs of the local development, such as increase small loans, promote to improve the small and mediumsized enterprise financing conditions. Official regional commercial banks have that kind of flexible advantage, so they can promote regional commercial banks to develop some specific financial business, so as to realize differentiation in various area and large commercial banks. But in the past few decades our country's regional commercial banks also influenced by separate operation mode, and tried to choose comprehensive management pattern in recent years, but they're blocked by certain development limits. Therefore, regional commercial banks should analysis its advantage as soon as possible, and then according to financial market and financial needs to develop business cooperation with different financial institutions, so as to realize integrated management mode which is based on the business cooperation.

\section{THE PRESENT SITUATION AND PROBLEMS OF COMMERCIAL BANKS’ BUSINESS MODEL IN CHINA}

With the constant innovation of China's financial industry, the original independent separate operation began to change, and the dividing line between each originally independent financial institutions become blurred, some of the commercial banks invest securities and insurance, and some insurance invest bank, the reason why our country's 
commercial bank changed is because the traditional mode of operation has created great cost, at the same time it also promoted the financial risk, so it is a very effective method to reduce the cost and risk by mixing business model. To develop comprehensive management pattern has at least the following four effects. The first is to guarantee the benefit of banks grow effectively; The second is through the integrated management which can effectively enhance the market position of commercial banks; The third is through the mixed management, commercial banks can promote the exist business growth and expand further potential bank business; Fourth, the integrated management of commercial banks can effectively promote the comprehensive quality of bank industry's talents, then enhance the market competitiveness of commercial banks. Although commercial banks through integrated management can effectively improve its core competitiveness, but in the actual development there are still many problems exist in the process, there are mainly embodied in the following several aspects.

\section{A. Commercial banks' comprehensive business model is relatively elementary}

Because in the past, our country's commercial bank interval in strict management for a long time, so our commercial banks will inevitably influenced by the original decentralized management mode in the process of implementing innovative integrated management, it is very difficult to make the comprehensive management pattern deep into the commercial bank system. So many commercial banks' promoting comprehensive management is more concerned about short-term and narrow phase, so it's easy to have interest conflicts, and it is difficult to establish a long-term strategic partnership of cooperation in the commercial bank system. And interest conflicts will produce noticeable negative effect on further development of comprehensive management pattern.

\section{B. Commercial banks' comprehensive business model regulatory system is not perfect}

Under the new period, the biggest way for commercial banks to innovate is to change the original decentralized management model into the integrated business model. But the subsequent is related to financial risk management. Although comprehensive management mode can effectively diluted commercial banks operating costs and expand their business scope, but it also brings more risk of diversified to commercial banks, and a lot of risk are highly concealment, apart from credit risk and liquidity risk under traditional business model, also including the risk of interest conflicts and comprehensive trading risk, so it needs more perfect risk management to better promote commercial banks to develop under the integrated management mode. But regulatory risk in commercial banks is not comprehensive and innovative business model doesn't have equal risk management innovation, so it is difficult to provide effective regulation on the diversity of the current risk.

\section{Lack of professional talents under integrated management mode}

Because the integrated business model taken by commercial banks, it will involve cross-sector management talent, the requirements for talents' comprehensive quality becomes more and more high, and these professionals also need to have multiple financial industry experience, but in the past dozens of years, our country adopts strict separation management pattern, makes talent of the financial sector become obvious simplification, so it is difficult to meet the demand for professional talents under current integrated management mode. Not to say the current talented person's training work has not been effectively carried out related to the comprehensive financial and it did not get the deserved attention, which creates the situation that current commercial banks lack of professional talents and it is difficult to meet the transformation and innovate of commercial banks business model.

\section{The BANKING Business Model STRATEGY}

\section{A. Promote business model transformation}

Business model transformation mainly embodied in intensive, flattening and specialization. The intensification of commercial banks means by computer and information technology, it can make homogeneity, professional business implement large-scale integration, makes management and operation more concentrated, through intensification to realize the unification of the quality and efficiency; Flat refers to the flattening organization management. Intensive is correlated with flat; the higher the Intensive degree is, the higher the flat level is. While realizing intensive it can gradually implement institutions' flattening at the same time, decrease intermediate level, shorten the decisionmaking chain, reduce resource consumption, make the decision and management closer to the market, close to the customer, and improve the level of decision-making and service.

\section{B. Promote commercial banks to change the pattern of economic growth}

The corresponding change of banks' management mode is the change of growth pattern, which is the purpose of changing management model, as well as the change of business model. The change of growth mainly embodied in becoming "three types". The first is "product quality". In the past period, the development way of the commercial bank business is to improve the efficiency by enlarging the scale, which is the scale efficiency. Due to the challenges of deconstruction optimization that current domestic economy face, and the economic development pattern is close to pursue the connotation development, corresponding, to realize the benefit growth, the commercial banks had already faced constraints through enlarging the scale, more important is through improving the operation quality. 


\section{Promote the integration of financial resources; strengthen the financial support for economy}

To expand the scope of business, develop and integrate bank business as the main content of commercial banks business model transformation is an important means as a response to the crisis, its purpose is to enhance financial support for economic development, to counter the influence of external shocks. To promote the sustainable development of economy, they should not only follow customer's actual demand to the development and innovation of financial products and services, speed credit's way of innovation, provide convenience for enterprises to raise funds, strengthen the innovation of organization and management mode, promote inter-bank cooperation, implement the domestic financial resources integration, at the same time play a role in financial support for the "San Nong" policy and solve the financing difficulties of small and medium-sized enterprises.

\section{Promote commercial bank business model structure reconstruction}

In order to reduce commercial banks' operating costs and improve efficiency, and to enhance competitiveness, domestic commercial banks should follow the requirements of specialized and intensive business model to reposition and structure reconstruction, promote the development of some big universal banks and at the same time train small and medium-sized banks as well as private banks, and speed up the development of the banking industry to become "leader" or "manager". Commercial banks can become a "universal retail bank", and then become a "universal bank". For now, the domestic commercial banks and other banks and non-bank institutions should carry out a variety of cooperation, and take advantage of external resources in each step of the value chain, improve the overall competitive advantage, especially those institutions with channel advantages to form strategic alliances; Small and medium-sized banks and private banks are just like the "channel" in the value chain, the domestic urban commercial banks, rural commercial banks, cooperative banks and rural credit cooperatives, should avoid falling into the "conveniently small" situation, and take the professional road.

\section{THE REFORM DIRECTION OF MANAGEMENT MODE IN THE FUTURE}

From the perspective of the interest requirements of commercial banks, Chinese commercial banks under the process of the decentralized management model can be called an improved process, because it was at the expense of the vested interests of commercial banks, so at this time the commercial bank system is unlikely to reach a state of equilibrium. This unbalanced state showed that formal system arrangement of commercial banks supply are shortages, it hinder the profit of business activities of commercial banks, also it increases the cost of business innovating activities, leads to low efficiency of commercial banks. Along with the development of the financial and economic globalization, the disadvantage of decentralized management increasingly exposed, but the system choice set may expand or narrow due to changes in government policy, therefore, it can gradually let go of the scope of commercial banks' business under the separate operation mode.

From the bank's point of view, the management system is related to the banks' profit and loss, the bank management system as the main part of formal banking system arrangement, the efficiency of the financial system and the efficiency macro economic is closely related, and it is also closely related to national security and social stability. The benefit bought from the mixed management pattern has great attraction to commercial banks, especially new type of commercial banks in China, so you should actively create conditions to transit to mixed operation, and it is imperative that people should not decentralized management absolutely, they should leave room for financial innovation in the process of implementation.

From the international environment, under the environment that most countries in the world are implementing mixed operation. The efficiency gap between China's banking sector and the banking industry in terms of the system and the technology is widening, and in the end we won't develop in the same level, which makes us become extremely competitive disadvantage when our country's bank are participating in the competition of international banking business, introducing foreign Banks, and opening financial market, formal business model for our country are earlier advanced at present. At present, considering the limits of commercial banks in talent, technology, capital investment, customer's needs, etc, can not meet the ideal demand of mixed management model, therefore, commercial banks must not only pay attention to improve the technical level and business innovation ability, but also to improve banks' internal and external innovation incentive system. Finally, the mixed management pattern is on the premise that banks and financial regulatory authorities and social security system enhance the risk control ability, so banks' competitiveness and financial regulation ability is the necessary condition commercial banks to implement institutional change in our country.

\section{CONCLUSIONS}

With the development of the society and the progress of economy, our country's enterprises face more serious situation in the process of present development, such as effective control for enterprise's financial risk management, which plays important role in the smooth development of the enterprise, to sum up, the enterprise risk management and financial management has both connection and difference, in the process of the actual management, you should combine with the of enterprises' practical development to display, thus can be more conducive to the healthy development of the enterprise. 


\section{REFERENCES}

[1] Guo Mang. The commercial bank business model innovation and transformation of research [J]. Journal of new financial, 2012 preceding: 41-43.

[2] Fei Jingya. Analyses the commercial bank financial innovation in the new period [J]. Foreign investment in China, 2012, 20:42.

[3] Zhou Qihong. Review and development trend of China's commercial banks business model [J]. Journal of theory and practice of finance and economics, 2002, S3:44-46.
[4] Zhihong Guo. The development of our country commercial bank management pattern and prospects [J]. Journal of hunan school of administration, 2009 01:71-72.

[5] Zhan You. Especially about the future of commercial bank management mode of thinking [J]. Journal of financial times, 2009,09:45 to 47.

[6] Wu Dongli. Modern commercial bank management pattern composition analysis [J]. Journal of commercial age, 2011, 29:75-77.

[7] Liu Baoyu. Commercial bank management pattern in the new period analysis [J]. J, 2014:90 + 81 . 